\title{
Ivabradine Hydrochloride
}

\author{
National Cancer Institute
}

\section{Source}

National Cancer Institute. Ivabradine Hydrochloride. NCI Thesaurus. Code C148546.

The hydrochloride salt form of ivabradine, an orally bioavailable, hyperpolarizationactivated, cyclic nucleotide-gated (HCN) channel blocker, with negative chronotropic activity. Upon administration, ivabradine selectively binds to the intracellular portion of the HCN channel pore and blocks HCN channels in the pacemaker cells within the sinoatrial (SA) node. This inhibits the If (funny) pacemaker ion current, prevents the inward flow and intracellular accumulation of positively charged ions, reduces pacemaker activity and slows diastolic depolarization. This decreases heart rate, reduces myocardial oxygen demand and allows more time for blood to flow to the myocardium without affecting cardiac contractility. HCN channels, mixed sodium $(\mathrm{Na}+)$ and potassium $(\mathrm{K}+)$ channels that carry the inward If current, play a key role in the regulation of pacemaker firing rate in the SA node. The If pacemaker current, the inward flow of positively charged $\mathrm{Na}+-\mathrm{K}+$ ions, initiates the spontaneous diastolic depolarization phase and modulating heart rate. 